\title{
Improved p-q Harmonic Detection Method for Hybrid Active Power Filter
}

\author{
Chau Minh Thuyen \\ Faculty of Electrical Engineering Technology, Industrial University of Ho Chi Minh City, Viet Nam
}

\begin{abstract}
Article Info
Article history:

Received Jun 23, 2017

Revised Feb 10, 2018

Accepted Jul 16, 2018

\section{Keyword:}

Fuzzy logic

Harmonic detection

Harmonic filter

Hybrid active power filter

P-q theory

ABSTRACT

The accurate determination of the load harmonic current is one of the important factors, it decides to effect of harmonic filtering and reactive power compensation for Hybrid Active Power Filter. The p-q harmonic detection method has been widely used in determining the harmonic currents of Hybrid Active Power Filter. However, when using this method, the dynamic response of Hybrid Active Power Filter in the transient period will have a large transient time and overshoot whenever the load changes abruptly. Therefore, in this paper an improved $\mathrm{p}-\mathrm{q}$ harmonic current detection method based on fuzzy logic is proposed, which aims to reduce the overshoot and transient time in transient duration of Hybrid Active Power Filter. In order to compare the dynamic response of conventional and improved $\mathrm{p}-\mathrm{q}$ harmonic detection methods, simulation results have demonstrated that: the proposed method has a shorter response time, the magnitude of the supply current in the transient time is smaller and the overshoot of the fundamental active and reactive power components is very small. This has a practical significance that contributes to the stability of the Hybrid Active Power Filter system.
\end{abstract}

Copyright (C) 2018 Institute of Advanced Engineering and Science. All rights reserved.

\section{Corresponding Author:}

Chau Minh Thuyen,

Faculty of Electrical Engineering Technology,

Industrial University of Ho Chi Minh City,

12 Nguyen Van Bao Street, 4 Ward, Go Vap District, Ho Chi Minh City 700000, Viet Nam.

Email: chauminhthuyen@iuh.edu.vn

\section{INTRODUCTION}

The issue of power quality is becoming a major problem in the power system. Countries on the world consider this to be one of the key criteria that determine the survival of an electrical system. The Hybrid Active Power Filter (HAPF) is known as a device for effective harmonics filtering and reactive power compensation on the power systems [1]-[3]. However, the effectiveness of HAPF depends on many factors such as: filter structure, calculation parameters, control method, control strategy, harmonics detection method, etc. This paper deals with a key issue that decides the correctly operating of HAPF. That is the harmonic current detection method.

There are many harmonic detection methods have been proposed for HAPF. Traditional harmonic detection methods include: the low-pass filter (LPF) [4],[5], high-pass filter (HPF) [6], fast Fourier transform [7] and p-q instantaneous power theory [8],[9]. The low-pass and high-pass filters have slow response and only a slight variation of frequency will also result in a significant phase shifting. The disadvantage of Fast Fourier Transform method is that it is not flexible to load changes because the sampling frequency has been fixed. The most common is the p-q harmonic detection method. This method has the advantage of being simple, easy to implement. However, it also has many disadvantages such as: transient time is large; result is inaccurate if the three-phase source is not ideal, and the overshoot at the transient period is large if the load changes with large amplitude and rapidly. The unideal three-phase source can be overcome by using the 
phase-locked loop (PLL). In summary, the p-q method is not suitable for fast changing and large capacity, such as large power drive systems [10],[11]. To improve the accuracy of the p-q harmonic detection method, a few articles have proposed by using the neural network [12],[13]. With the use of neural networks to determine harmonic currents, it has the advantage of giving accurate results in steady-state if the training algorithm is used well. However, there are shortcomings that the mathematical model is too complex, the ability to respond too slowly. Therefore, it is less used. Another method is FBD (Fryze-BuchholzDpenbrock) method [14]-[16], which is based on the sliding-window iterative algorithm. This method has the advantage of not using phase-locked loop block and skip low-pass filter. Even so, it has the disadvantages of complex and slow response. The harmonic detection method uses the Fuzzy Least Mean Squares algorithm has been introduced [17],[18] and has also improved accuracy in steady-state. However, this method has a response in transient period is slow, large overshoot when the load changes rapidly.

In short, the above listed methods have disadvantages of large transient time and it is difficult to reduce the current amplitude during the transient conditions. In this paper, an improvement of the traditional $\mathrm{p}-\mathrm{q}$ harmonic detection method is made. The purpose of this improvement is to reduce the overshoot, transient time. From the mathematical analysis of the traditional p-q method, we find that its disadvantage is that it depends on the source voltage and the LPF. From there, a fuzzy regulator is integrated into the traditional p-q harmonic detection method to adjust the DC components of the active power and reactive powers to near the desired value. From this, the amplitude of the source current has not overshoot when the load is changing rapidly and with large amplitude, while the transient time is greatly reduced. The structure of the paper consists of four parts: part 1 gives an overview of the research problem, the p-q harmonic detection method and its disadvantage are analyzed in part 2, part 3 is the improved p-q harmonic detection method, part 4 is the results of simulation and discussion, the conclusions are presented in part 5.

\section{P-Q HARMONIC DETECTION METHOD AND ITS DISADVANTAGE}

The p-q harmonic detection method is proposed by Akagi [8] and can be summarized as in Figure 1.

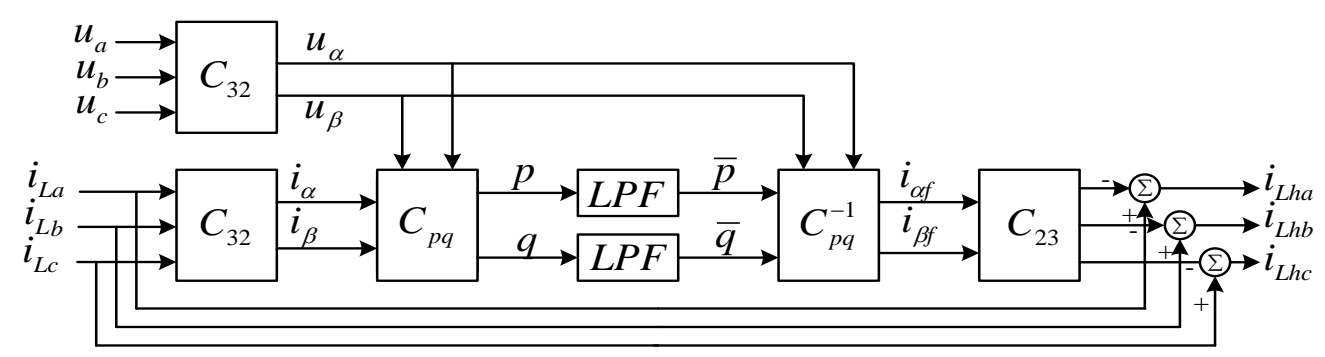

Figure 1. The principle diagram of $\mathrm{p}-\mathrm{q}$ harmonic detection method

Suppose, three-phase instantaneous voltage is symmetric:

$$
\left\{\begin{array}{l}
u_{a}=\sqrt{2} U_{1} \sin (\omega t) \\
u_{b}=\sqrt{2} U_{1} \sin \left(\omega t-\frac{2 \pi}{3}\right) \\
u_{c}=\sqrt{2} U_{1} \sin \left(\omega t+\frac{2 \pi}{3}\right)
\end{array}\right.
$$

And three-phase instantaneous current of load is

$$
\left\{\begin{array}{l}
i_{L a}=\sum_{n=1}^{\infty} \sqrt{2} I_{n} \sin \left(n \omega t+\varphi_{n}\right) \\
i_{L b}=\sum_{n=1}^{\infty} \sqrt{2} I_{n} \sin \left[n\left(\omega t-\frac{2 \pi}{3}\right)+\varphi_{n}\right] \\
i_{L c}=\sum_{n=1}^{\infty} \sqrt{2} I_{n} \sin \left[n\left(\omega t+\frac{2 \pi}{3}\right)+\varphi_{n}\right]
\end{array}\right.
$$


According to Figure 1, we can see that

$$
\left[\begin{array}{l}
u_{\alpha} \\
u_{\beta}
\end{array}\right]=C_{32}\left[\begin{array}{l}
u_{a} \\
u_{b} \\
u_{c}
\end{array}\right]=\sqrt{3} U_{1}\left[\begin{array}{l}
\sin \omega t \\
-\cos \omega t
\end{array}\right]
$$

Similarly, for three-phase instantaneous current is $i_{L a}, i_{L b}, i_{L c}$

$$
\left[\begin{array}{l}
i_{\alpha} \\
i_{\beta}
\end{array}\right]=C_{32}\left[\begin{array}{l}
i_{L a} \\
i_{L b} \\
i_{L c}
\end{array}\right]=\sqrt{3}\left[\begin{array}{l}
\sum_{i=1}^{\infty} I_{n} \sin \left(n \omega t+\varphi_{n}\right) \\
\sum_{i=1}^{\infty} \mp I_{n} \cos \left(n \omega t+\varphi_{n}\right)
\end{array}\right]
$$

$$
\text { With } C_{32}==\sqrt{\frac{2}{3}}\left[\begin{array}{ccc}
1 & -\frac{1}{2} & -\frac{1}{2} \\
0 & \sqrt{\frac{3}{2}} & -\sqrt{\frac{3}{2}}
\end{array}\right]
$$

According to Figure 1, we have:

$$
\left[\begin{array}{l}
p \\
q
\end{array}\right]=\sqrt{3} U_{1}\left[\begin{array}{ll}
\sin \omega t & -\cos \omega t \\
-\cos \omega t & -\sin \omega t
\end{array}\right]\left[\begin{array}{l}
i_{\alpha} \\
i_{\beta}
\end{array}\right]
$$

Using low-pass filter to filter take the DC components of $\mathrm{p}$ and $\mathrm{q}$.

$$
\begin{aligned}
& \left\{\begin{array}{l}
p=\bar{p}+\tilde{p} \\
q=\bar{q}+\tilde{q}
\end{array}\right. \\
& {\left[\begin{array}{l}
\bar{p} \\
\bar{q}
\end{array}\right]=3\left[\begin{array}{l}
U_{1} I_{1} \cos \left(-\varphi_{1}\right) \\
U_{1} I_{1} \sin \left(-\varphi_{1}\right)
\end{array}\right]}
\end{aligned}
$$

Where: $U_{1}$ and $I_{1}$ are fundamental voltage and current root mean square components. From Figure 1 and the DC components $\bar{p}$ and $\bar{q}$, we can calculated the fundamental harmonics current components of the $i_{L a}, i_{L b}$, $i_{L c}$ following formula as

$$
\begin{aligned}
& {\left[\begin{array}{l}
i_{L a f} \\
i_{L b f} \\
i_{L c f}
\end{array}\right]=\frac{1}{3 U_{1}^{2}} C_{23} C_{p q}^{-1}\left[\begin{array}{c}
\bar{p} \\
\bar{q}
\end{array}\right]=\left[\begin{array}{l}
\sqrt{2} I_{1} \sin \left(\omega t+\varphi_{1}\right) \\
\sqrt{2} I_{1} \sin \left(\omega t-\frac{2 \pi}{3}+\varphi_{1}\right) \\
\sqrt{2} I_{1} \sin \left(\omega t+\frac{2 \pi}{3}+\varphi_{1}\right)
\end{array}\right]} \\
& \text { where } C_{23}=C_{32}^{T} ; C_{p q}=\left[\begin{array}{ll}
u_{\alpha} & u_{\beta} \\
u_{\beta} & -u_{\alpha}
\end{array}\right]
\end{aligned}
$$

From here, the harmonic current components can be determined as: 


$$
\left\{\begin{array}{l}
i_{L a h}=i_{L a}-i_{L a f} \\
i_{L b h}=i_{L b}-i_{L b f} \\
i_{L c h}=i_{L c}-i_{L c f}
\end{array}\right.
$$

From (8) we see that: p-q method has the disadvantage of depending on the supply voltage and lowpass filter (LPF). When source voltage is not ideal, PLL block must be used [6]. When the load has a variation rapidly in amplitude and phase angle, the LPFs will produce components $\bar{p}$ and $\bar{q}$ that contain unwanted components. As a result, the amplitude of the supply current increases dramatically in transient period, a large variation of active power and reactive power and easy to destabilize the system. In the p-q method, the low-pass filter (LPF) determines the accuracy of the method, when the cut-off frequency is chosen to be large, the transient time will decrease but the overshoot is large and the error is large. The cutoff frequency is small, the overshoot will decrease and the error in steady-state is small but the transient time will be very large. In real time applications, load changes rapidly over time, components $\bar{p}$ and $\bar{q}$ will change at different frequencies. From (6) we can rewrite:

$$
\left\{\begin{array}{l}
p=\bar{p}+K_{p}+\tilde{p} \\
q=\bar{q}+K_{q}+\tilde{q}
\end{array}\right.
$$

and (8) becomes:

$$
\left[\begin{array}{l}
i_{L a f} \\
i_{L b f} \\
i_{L c f}
\end{array}\right]=\frac{1}{3 U_{1}^{2}} C_{23} C_{p q}^{-1}\left[\begin{array}{l}
\bar{p}+K_{p} \\
\bar{q}+K_{q}
\end{array}\right]
$$

$\bar{p}$ and $\bar{q}$ will have step response. However, actual power will change due to system changes. The difference between the actual value and the reference value of $\bar{p}$ is called $\Delta \mathrm{p}$. Similarly, the difference between the actual value $\bar{q}$ and the reference value is called $\Delta \mathrm{q}$. Desired and actual variation of $\bar{p}$ and $\bar{q}$ are shown in Figure 2.

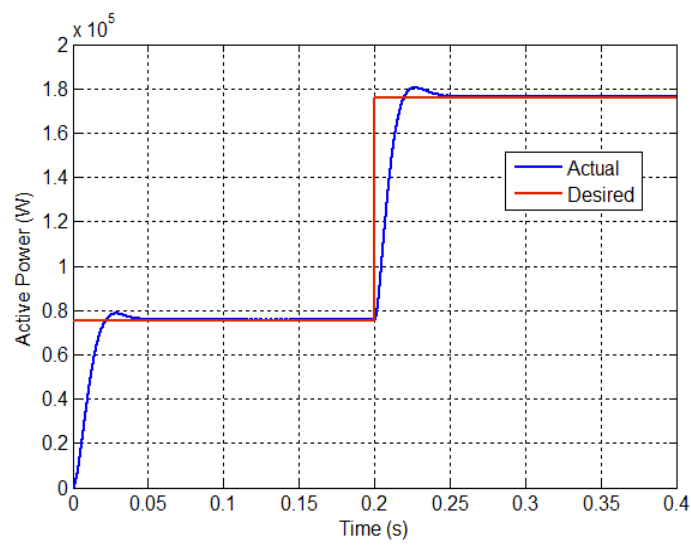

(a) Desired and actual variation of $\bar{p}_{\text {and }} \bar{q}$

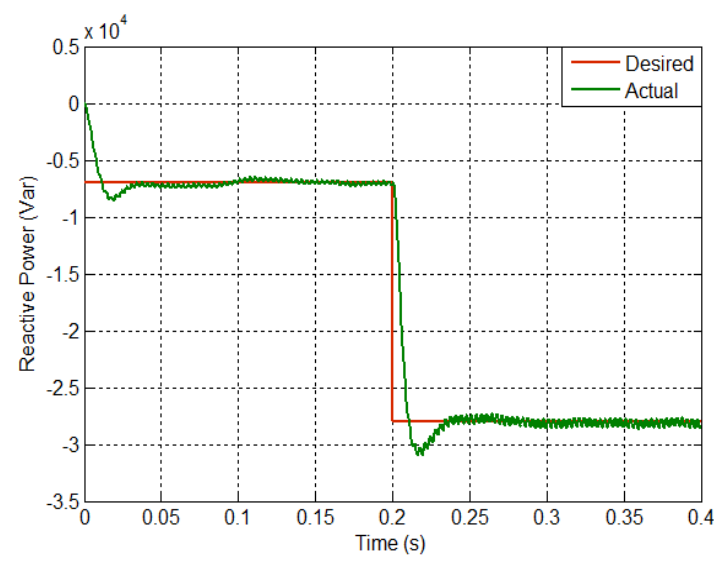

(b) Desired and actual variation of $\bar{p}_{\text {and }} \bar{q}$ Figure 2. Desired and actual variation of $\bar{p}$ and $\bar{q}$

From Figure 2, we see that in the transient period there is a discrepancy between the actual value and the reference value. When the load changes, the overshoot is high, which results in a sudden increase in the amplitude of the supply current, leading to system easy instability. 


\section{IMPROVED P-Q HARMONIC DETECTION METHOD}

To improve the overshoot and reduce the dynamic response time of the traditional $\mathrm{p}-\mathrm{q}$ harmonic detection method. An improved p-q harmonic detection method is given as in Figure 3.

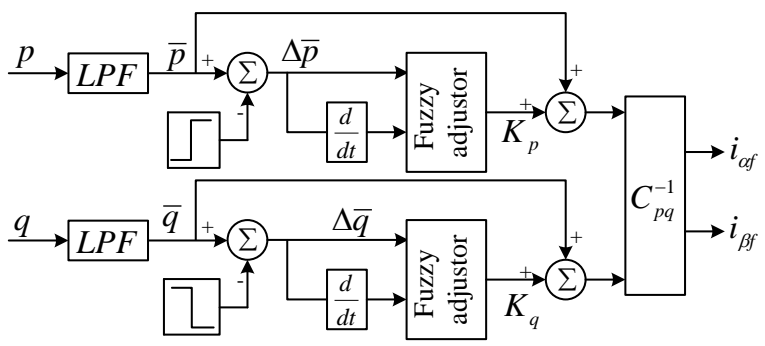

Figure 3. Improved p-q harmonic detection method

The p and q components after passing LPF will obtain the DC components are $\bar{p}$ and $\bar{q}$. The error between the actual value and the reference value of $\bar{p}$ and $\bar{q}$ is $\Delta \bar{p}$ and $\Delta \bar{q}$, and it is denoted as $\Delta($.) and its rate $\mathrm{d} / \mathrm{dt}$ is the inputs of the fuzzy regulator, the outputs of the fuzzy regulator are Kp and Kq. Thus (8) can be rewritten as follows:

$$
\left[\begin{array}{l}
i_{\text {Laf }} \\
i_{L b f} \\
i_{L c f}
\end{array}\right]=\frac{1}{3 U_{1}^{2}} C_{23} C_{p q}^{-1}\left[\begin{array}{l}
\bar{p}+K_{p} \\
\bar{q}+K_{q}
\end{array}\right]
$$

The inputs and outputs of the fuzzy regulator are showed into seven membership function: Negative Big (NB), Negative Medium (NM), Negative Small (NS), Zero (Z0), Positive Small (PS), Positive Medium (PM), Positive Big (PB) as shown in Figure 4, and fuzzy inference are shown in Table 1.

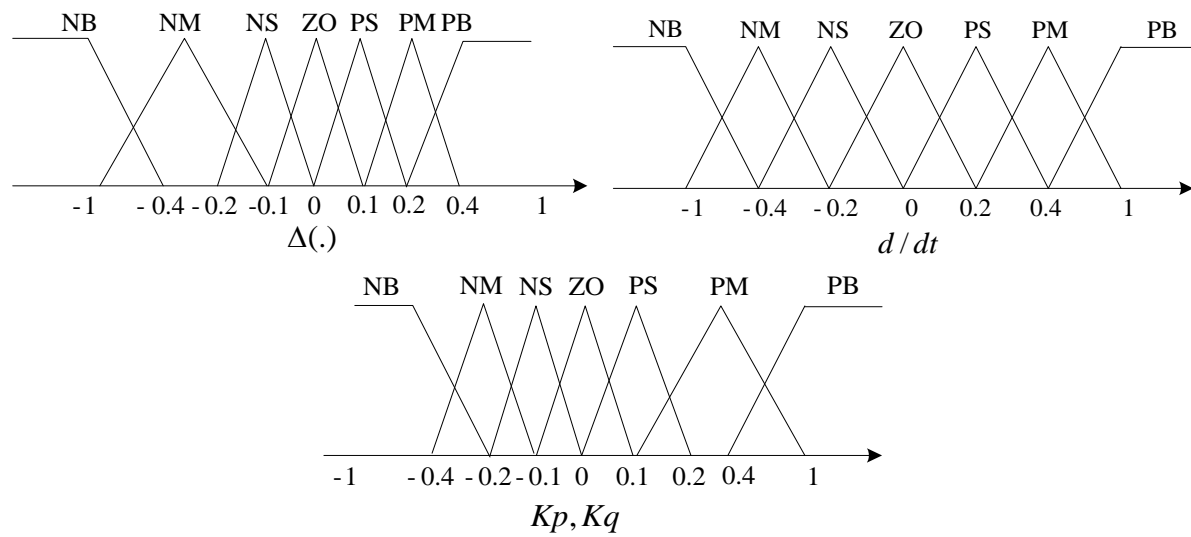

Figure 4. Membership functions of input/output

Based on Figure 2 and Figure 3, we have the control laws of $K_{p}$ and $K_{q}$ as follows:

1) If $\Delta()=$.0 , then $K_{p}, K_{q}$ must be zero.

2) If $\Delta($.$) is NS or PS, then K_{p}, K_{q}$ should be zero

3) For large value of $\Delta\left(\right.$.), a small $K_{p}, K_{q}$ is required and for small value of $\Delta$ (.), a large $K_{p}, K_{q}$ is required.

4) For positive values of $\Delta\left(\right.$.) and $d / d t$, negative values of $K_{p}, K_{q}$ are required and for negative values of $\Delta($.) and $d / d t$, positive values of $K_{p}, K_{q}$ are required. 
5) For positive values of $\Delta$ (.) and negative values of $d / d t$, negative values of $K_{p}, K_{q}$ are required and for negative values of $\Delta($.$) and positive values of d / d t$, positive values of $K_{p}, K_{q}$ are required.

Table 1. Fuzzy rules

\begin{tabular}{|c|c|c|c|c|c|c|c|c|}
\hline \multirow{2}{*}{\multicolumn{2}{|c|}{$K_{p}, K_{q}$}} & \multicolumn{7}{|c|}{$d / d t$} \\
\hline & & $N B$ & $N M$ & $N S$ & ZO & $P S$ & $P M$ & $P B$ \\
\hline \multirow{7}{*}{$\Delta()}$. & $N B$ & PB & PM & PM & PM & PS & PS & PS \\
\hline & $N M$ & $\mathrm{PM}$ & PM & PS & PS & PS & PS & PS \\
\hline & $N S$ & PS & Z0 & Z0 & Z0 & $\mathrm{Z} 0$ & Z0 & PS \\
\hline & ZO & Z0 & Z0 & Z0 & Z0 & Z0 & Z0 & $\mathrm{Z} 0$ \\
\hline & $P S$ & NS & Z0 & Z0 & $\mathrm{Z} 0$ & $\mathrm{Z} 0$ & Z0 & NS \\
\hline & $P M$ & NM & NM & NS & NS & NS & NS & NS \\
\hline & $P B$ & NB & NM & NM & NM & NS & NS & NS \\
\hline
\end{tabular}

\section{SIMULATION RESULTS AND DISCUSSION}

To demonstrate the effectiveness of the improved p-q harmonic detection method compared with the traditional p-q harmonic detection method, simulation results were performed on a 380V-50Hz HAPF model as shown in Figure 5.

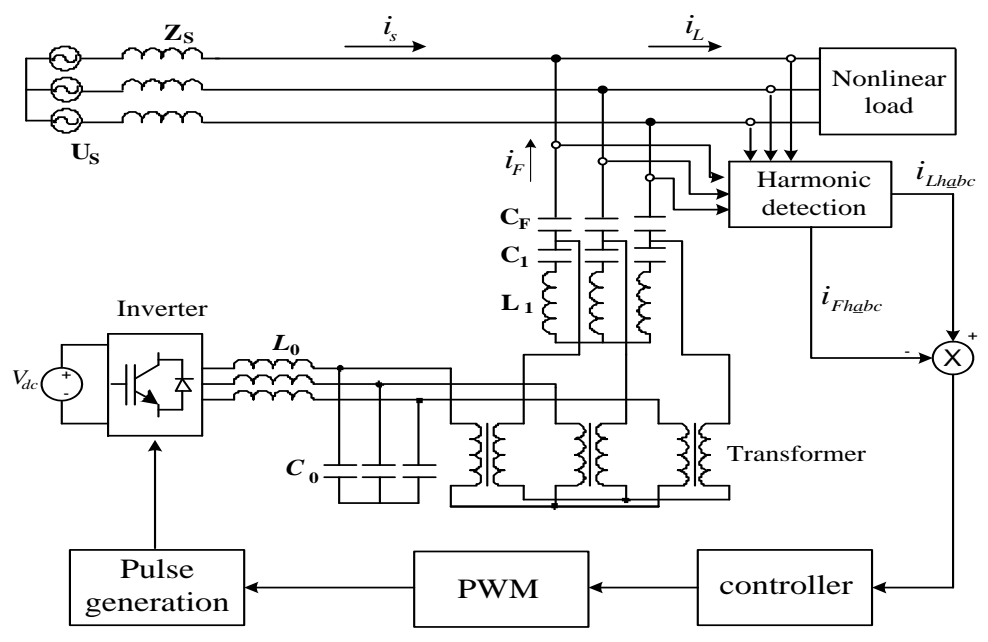

Figure 5. HAPF model

Nonlinear loads are modeled by a three-phase uncontrolled bridge rectifier with RLC load $(0 \div 0.2 \mathrm{~s})$ and then the load changes $(0.2 \mathrm{~s} \div 0.4 \mathrm{~s})$. The frequency spectrum of the load currents is shown in Figure 6 . DC components of active power and reactive power before and after load change are shown as in Figure 7.

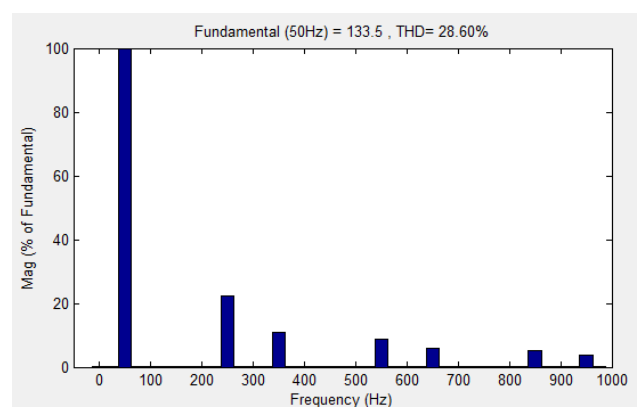

(a) Frequency spectrum of the load current before change

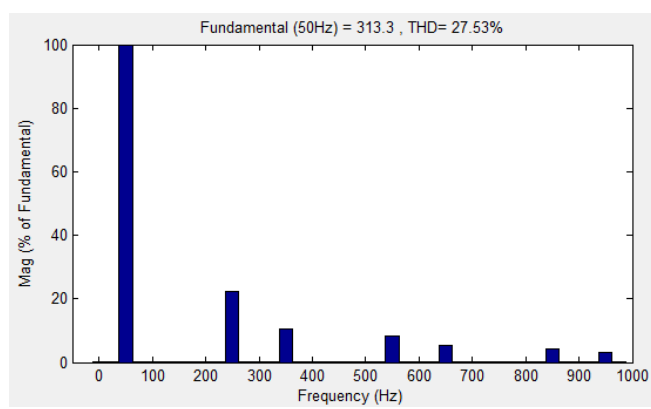

(b) Frequency spectrum of the load current after change

Figure 6. Frequency spectrum of the load current before and after change 


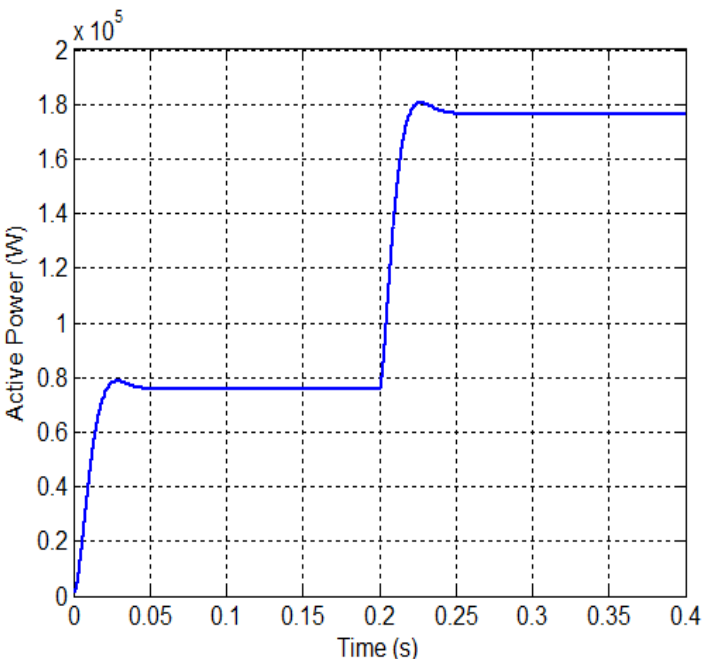

a) Response of $\bar{p}$ with the traditional p-q method

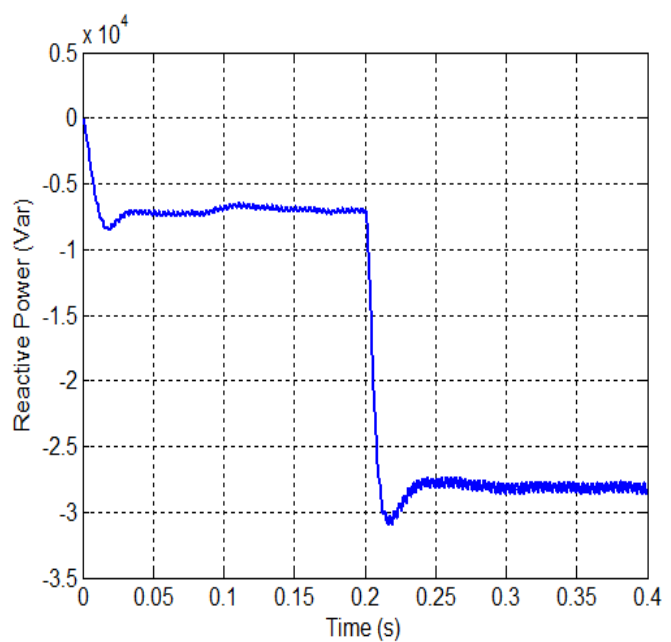

c) Response of $\bar{q}$ with the traditional p-q method

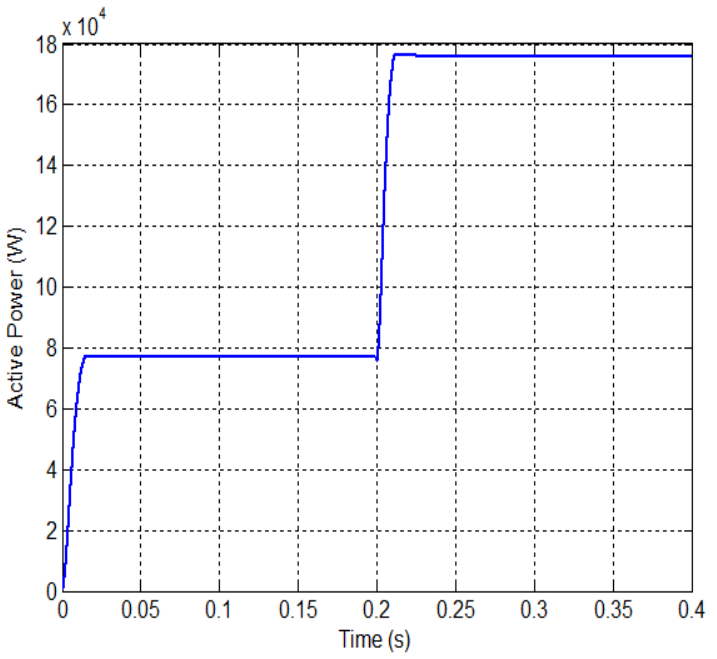

b) Response of $\bar{p}$ with the improved p-q method

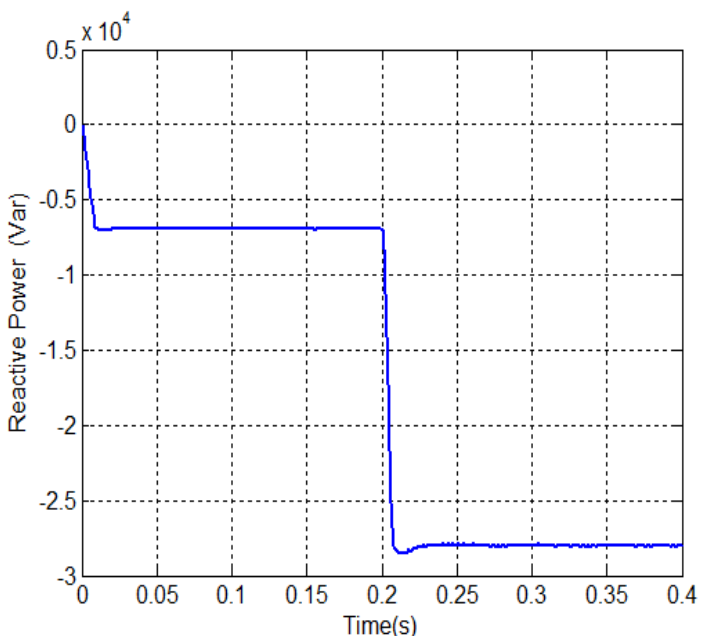

d) Response of $\bar{q}$ with the improved p-q method

Figure 7. Responses of $\bar{p}$ and $\bar{q}$

From Figure 7 we can compare the responses of $\bar{p}$ and $\bar{q}$ as shown in Table 2 and Table 3. The dynamic responses of the waveforms with the traditional p-q and improved p-q methods are shown in Figures 8 and Figure 9.

Table 2. Response of $\bar{p}$

\begin{tabular}{ccccc}
\hline & \multicolumn{2}{c}{$0.0 \mathrm{~s} \div 0.2 \mathrm{~s}$} & \multicolumn{2}{c}{$0.2 \mathrm{~s} \div 0.4 \mathrm{~s}$} \\
& transient time & overshoot & transient time & overshoot \\
\hline Traditional p-q & $0.05 \mathrm{~s}$ & $2.17 \%$ & $0.05 \mathrm{~s}$ & $3.4 \%$ \\
Improved p-q & $0.016 \mathrm{~s}$ & $0.3 \%$ & 0.025 & $0.5 \%$ \\
\hline
\end{tabular}

Table 3. Response of $\bar{q}$

\begin{tabular}{ccccc}
\hline & \multicolumn{2}{c}{$0.0 \mathrm{~s} \div 0.2 \mathrm{~s}$} & \multicolumn{2}{c}{$0.2 \mathrm{~s} \div 0.4 \mathrm{~s}$} \\
& transient time & overshoot & transient time & overshoot \\
\hline Traditional p-q & $0.025 \mathrm{~s}$ & $20.2 \%$ & $0.04 \mathrm{~s}$ & $21.13 \%$ \\
Improved p-q & $0.02 \mathrm{~s}$ & $0.42 \%$ & $0.02 \mathrm{~s}$ & $2 \%$ \\
\hline
\end{tabular}



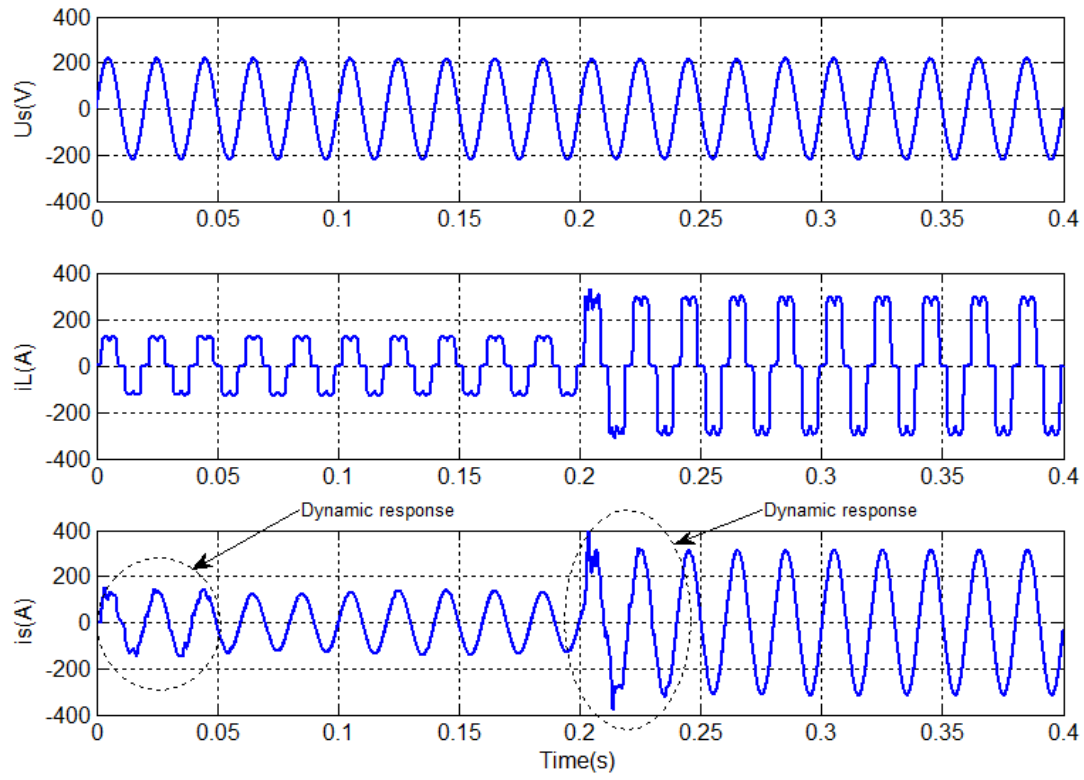

Figure 8. Dynamic response of waveforms with the traditional p-q method
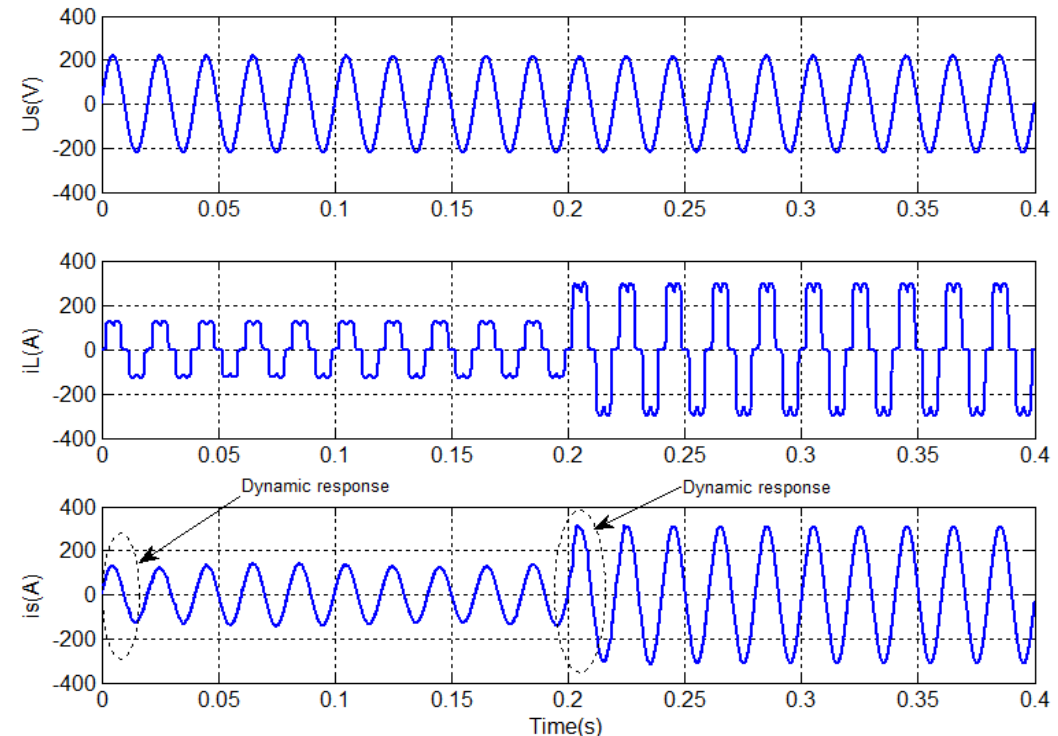

Figure 9. Dynamic response of waveforms with the improved p-q method

At $\mathrm{t}=0.2 \mathrm{~s}$ load is changed. From Figures 8 and Figure 9 we find that: with traditional p-q method, the transient time is $0.05 \mathrm{~s}(0 \mathrm{~s} \div 0.05 \mathrm{~s})$ and $0.04 \mathrm{~s}(0.2 \mathrm{~s} \div 0.24 \mathrm{~s})$, the overshoot when the load change is $27.67 \%$, the total harmonic distortion of the supply current in steady-state is $1.22 \%(0.1 \mathrm{~s} \div 0.2 \mathrm{~s})$ and $1.44 \%$ $(0.3 \mathrm{~s} \div 0.4 \mathrm{~s})$. When the improved $\mathrm{p}-\mathrm{q}$ method is used, the transient time is almost zero and $0.01 \mathrm{~s}(0.2 \mathrm{~s} \div$ $0.21 \mathrm{~s})$, the overshoot is almost zero when the load before and after change, total harmonic distortion of the supply current in steady-state is $1.21 \%(0.1 \mathrm{~s} \div 0.2 \mathrm{~s})$ and $1.42 \%(0.3 \mathrm{~s} \div 0.4 \mathrm{~s})$. In addition, the supply current of the proposed method is also compared to methods in [5],[6],[12],[13],[16] as summarized in Table 4, mainly compared in the transient duration. In summary, the simulation results demonstrate that the improved $\mathrm{p}-\mathrm{q}$ harmonic detection method has cancelled the disadvantages of the traditional p-q harmonic detection method, which aims to reduce the transient time, reduce the overshoot. This has great significance in improving the stability of the HAPF system. 
Table 4. Comparison of Supply Current between the Proposed Method and the Methods in [5],[6],[12],[13],[16]

\begin{tabular}{lcc}
\hline & $\begin{array}{c}\text { Transient } \\
\text { time (s) }\end{array}$ & $\begin{array}{c}\text { Overshoot } \\
(\%)\end{array}$ \\
\hline low-pass filter method [5] & 0.05 & 23.59 \\
High-pass filter method [6] & 0.05 & 22.9 \\
Neural method [12] & 0.02 & 25.7 \\
Active and reactive power method [13] & 0.04 & 0,00 \\
Improved FBD method [16] & 0.025 & 0.00 \\
Proposed method & 0.01 & 0.00 \\
\hline
\end{tabular}

\section{CONCLUSION}

This paper has made a development to the traditional $\mathrm{p}-\mathrm{q}$ harmonic detection method. This development aims to reduce the dynamic response time, to reduce the overshoot in the transient duration for HAPF. Compared to the low-pass filter, high-pass filter, neural, active and reactive power and improved FBD methods. Proposed method has proven clear effectiveness in the transient duration of HAPF. Furthermore, this study also contributed to improve the stability of the HAPF system when the load sudden change with a large amplitude. This approach will be a good solution for high power speed drive applications.

\section{REFERENCES}

[1] D. Janyavula and S. N. Saxena, "Unbalanced Variable Nonlinear Load Compensation Using Multiple Shunt Active Filters,” International Journal of Electrical and Computer Engineering (IJECE), vol. 5, pp. 896-904, 2015.

[2] Y. K. Latha, et al., "Control Strategy for Three Phase Shunt Active Power Filter with Minimum Current Measurements,” International Journal of Electrical and Computer Engineering (IJECE), vol. 1, pp. 31-42, 2011.

[3] N. S. Hasan, et al., "Harmonic Suppression of Shunt Hybrid Filter using LQR-PSO based," International Journal of Electrical and Computer Engineering (IJECE), vol. 7, pp. 869-876 , 2017.

[4] M. T. Chau, “Adaptive Current Control Method for Hybrid Active Power Filter," Journal of Electrical Engineering, vol. 67, pp. 343-350, 2016.

[5] M. T. Chau, et al., "Novel Control Method a Hybrid Active Power Filter with Injection Circuit Using a Hybrid Fuzzy Controller,” Journal of Power Electronics, vol. 12, pp. 800-812, 2012.

[6] M. Chau, et al., "Online Control Method with Time-Delay Compensation for Hybrid Active Power Filter with Injection Circuit,” IET Power Electronics, vol. 5, pp. 1472-1482, 2012.

[7] P. M. Nicolae and D. L. Popa, "Real-Time Implementation of Some Fourier Transform Based Techniques for Fundamental Harmonic Detection Using Dspace,” $18^{\text {th }}$ European Conference on Power Electronics and Applications (EPE'16 ECCE Europe), pp. 1-7, 2016.

[8] H. Akagi, et al., "Generalized Theory of Instantaneous Reactive Power and Its Application," Electrical Engineering of Japan, vol.103, pp. 483-490, 1983.

[9] F. H. Benali and F. Azzouz, "Comparison of Instantaneous Reactive and Notch Filter Algorithms Seven Level Parallel Active Filter,” International Journal of Electrical and Computer Engineering (IJECE), vol. 7, pp. 17791788, 2017.

[10] N. S. Rao and H. J. Jayatheertha, "Modeling and Simulation of Various SRF Methods for Shunt Active Power Filter and Application to BLDC Drive,” International Journal of Advanced Engineering Research and Studies, vol. 1, pp. 18-22, 2012.

[11] L. Asiminoaei, et al., "Evaluation of Harmonic Detection Methods for Active Power Filter Applications,” IEEE Applied Power Electronics Conference and Exposition, vol. 1, pp. 635-641, 2005.

[12] R. Dehini, et al., "The Harmonics Detection Method Based on Neural Network Applied to Harmonics Compensation,” International Journal of Engineering, Science and Technology, vol. 2, pp. 258-267, 2010.

[13] D. O. Abdeslam, et al., "Harmonic Identification Based on ANN: A Comparative Study," $9^{\text {th }}$ International Conference on Engineering Applications of Neural Networks - (EANN'2005), Lille, France, pp. 24-31, 2005.

[14] Wenjuan L., et al., “Active Power Filter Based on FBD Current Detection," $11^{\text {th }}$ International Conference on Computer Science \& Education (ICCSE), pp. 839-843, 2016.

[15] C. Yuan, et al., "Improved FBD Reactive Power and Harmonic Current Detecting Method Based on Voltage Sequence Decomposition,” $12^{\text {th }}$ IEEE International Conference on Electronic Measurement \& Instruments (ICEMI), pp. 567-572, 2015.

[16] W. Liu, et al., "Harmonic Current Detection Algorithm Based on the Improved FBD Method and Its Application in Active Power Filters,” Asia-Pacific Power and Energy Engineering Conference, pp. 1-5, 2012.

[17] Q. Yilong, et al., "An Adaptive Harmonic Detection Method Using Fuzzy LMS Algorithm,” Automation of Electric Power Systems, vol. 32, pp. 71-75, 2008.

[18] L. Hui and Z. Yunping, "A Novel Adaptive Harmonic Detection Algorithm Based Variable Step size LMS," Automation of Electric Power Systems, vol. 29, pp. 69-73, 2005. 


\section{BIOGRAPHY OF AUTHOR}

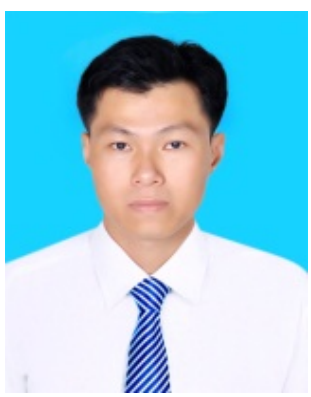

Chau Minh Thuyen was born in Binh Dinh, Vietnam, on June 6, 1977. He received his B.S. and M.S. from the Da Nang University of Technology, Da Nang, Viet Nam, and the University of Technical Education Ho Chi Minh City, Ho Chi Minh City, Viet Nam, in 2001 and 2005, respectively, and Ph.D. from Hunan University, China, in 2012. Since 2004, he has been a Lecturer at Industrial University of Ho Chí Minh City, Viet Nam. His current research includes power electronics, electric power savings, reactive power compensation, and active power filters. 